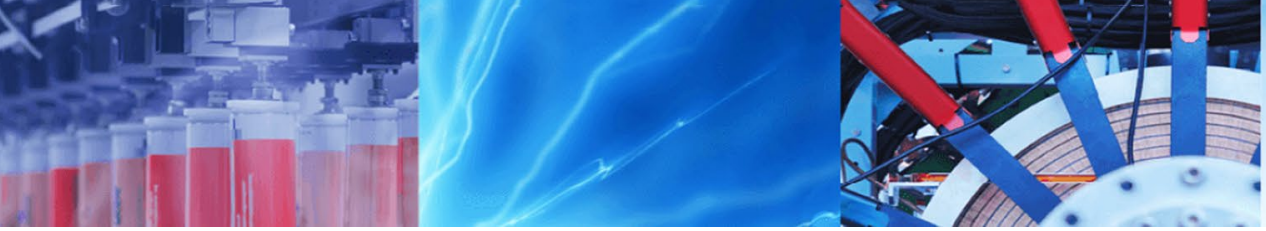

Research Article

\title{
Modifying the thermomechanical properties of electrospun fibres of poly-vinyl cinnamate by photo-cross-linking
}

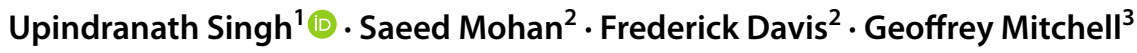

(c) Springer Nature Switzerland AG 2018

\begin{abstract}
We explore the effects of cross-linking on some thermal and mechanical properties of polymer nanofibers of poly-vinyl cinnamate which were electro-spun from 1,2 dichloroethane. Scanning electron microscopy performed on the fibres revealed smooth fibres which were devoid of beading or ribbon-type features. When cross-linked, the Young's moduli and glass transition temperatures of the fibres increase, owing to the formation of new covalent bonds which leads to higher overall binding energies. The glass transition temperatures increased by $20 \mathrm{~K}$ after $1 \mathrm{~h}$ of photo-polymerization while the Young's modulus increased by $50 \%$ for the same exposure time. The glass transition temperatures as well as the heats of enthalpy indicate that a significant portion of cross-linking occurs within the first $10 \mathrm{~min}$ of exposure.
\end{abstract}

Keywords Electro-spinning · Cross-linking · Photo-polymer · Young's modulus · Enthalpy · Glass transition

\section{Introduction}

Electrospinning is a relatively simple technique for generating continuous fibres whose diameters, depending on experimental parameters, can approach nanoscale dimensions [1]. Typically, the technique involves forcing a polymer solution or melt through the tip of a metallic nozzle which also acts as an electrode. The charged jet of solution that emerges from the nozzle is attracted by a counter electrode which is suitably located. During its flight to the counter electrode, the diameter of the jet decreases owing to the combined effects of solvent evaporation and field-induced stretching. If the repulsive forces within the jet stream exceed the cohesive forces, the single jet divides into smaller jets (splaying). If splaying does not occur, extremely thin fibres form, owing to the elongation of the single jet. However, both splaying and elongation seem to occur simultaneously [2].
Several parameters, including the strength of the applied electric field, dielectric constant of the solvent, viscosity of the melt, flow rate, nozzle diameter and type of collector directly influence the dimensions and topology of the electrospun fibres [1, 3]. A rotating drum collector which winds the fibres around its circumference offers better aligned fibres than a flat-plate collector [4]. The pertinent aspects of the principles of electrospinning are captured in some recent review papers [4-10]. Owing to their unique properties, such as, very large surface areas, enhanced mechanical properties, tunable diameters and flexible surface functionalities, electrospun fibers have found applications in many diverse fields. These include, among others, catalysis [11-14], tissue engineering [15-17], filtration [18-22], protective textiles [23-25] and sensors [26-28].

We explore the effects of controlled UV exposure on the thermal and mechanical properties of electro-spun polymer fibres of poly-vinyl cinnamate (PVCN) which is a

$\triangle$ Upindranath Singh, upindranath.singh@cavehill.uwi.edu; Saeed Mohan, s.d.mohan@reading.ac.uk; Frederick Davis, f.j.davis@reading.ac.uk; Geoffrey Mitchell, geoffrey.mitchell@ipleiria.pt | ${ }^{1}$ Physics Department, University of the West Indies, P.O. Box 64, Bridgetown,

Barbados. ${ }^{2}$ Department of Chemistry, University of Reading, Reading RG6 6AD, UK. ${ }^{3}$ Centro Empresarial da Marinha Grande Rua de Portugal-Zona Industrial, 2430-028 Marinha Grande, Portugal. 
copolymer of vinyl cinnamate and vinyl alcohol. PVCN was chosen since it readily forms smooth fibres, is highly sensitive to ultra violet (UV) radiation and undergoes photodimerization without a photo-initiator [29]. PVCN undergoes a random cross-linking photo-addition between a UV excited cinnamoyl group of a polymer chain and that of a similar unexcited group on the same or a different chain to form a cyclobutane ring [30] as shown in Fig. 1. Neither the $\mathrm{C}-\mathrm{H}$ nor the carbonyl group is expected to be excited by the same UV light and cross-linking involves only the $\mathrm{C}=\mathrm{C}[29,30]$. PVCN has a glass transition of $\sim 80^{\circ} \mathrm{C}$ and is stable up to $200^{\circ} \mathrm{C}$ [29]. Above this temperature, thermal degradation as a result of the separation of the cinnamate unit from the main chain occurs and thermally-induced cross-linking takes place.

When exposed to UV radiation, PVCN and its derivatives have been found to align liquid crystals in a direction perpendicular to the electric vector of the polarized light. Owing to this feature PVCN offers potential in display technology and hence the interest in the photo-chemistry of PVCN and its derivatives [31, 32].

\section{Experimental}

PVCN was purchased from Polysciences, Inc. (USA) and used as obtained. Electrospinning was performed on a uniform solution of PVCN in dry 1,2 dichloromethane (DCE), $18.8 \%$ by weight. The technique has been described completely elsewhere [33] and hence, only the pertinent details will be outlined here. The polymer solution was housed in a $5 \mathrm{ml}$ glass syringe to which was attached a 22 gauge metallic needle of $0.41 \mathrm{~mm}$ internal diameter. The needle served as one electrode. The flow rates were controlled by a calibrated pump which delivered an optimum flow rate of $0.13 \mathrm{ml} \mathrm{min}{ }^{-1}$. The electrospun fibres were collected by a rotating and grounded cylindrical

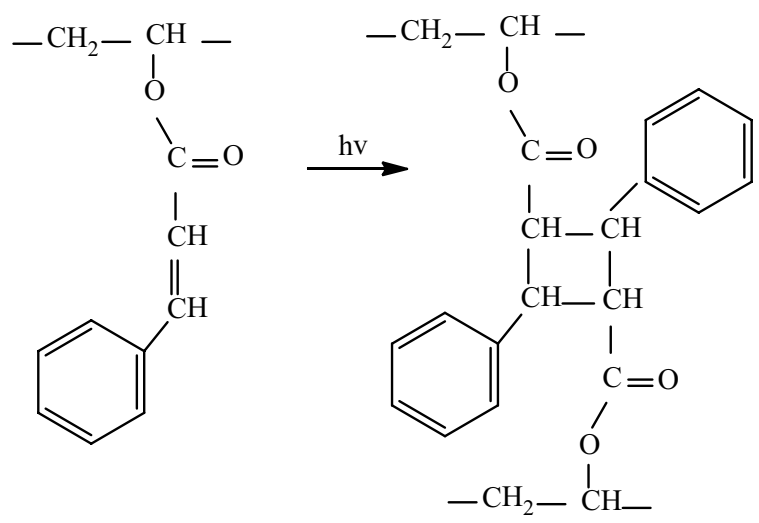

Fig. 1 Photo-dimerization of PVCN in the presence of UV light to yield the cyclobutane ring collector which has a diameter of $3.2 \mathrm{~cm}$. A fixed tangential velocity of $4.0 \mathrm{~ms}^{-1}$ was used throughout. The needlecollector separation was $10 \mathrm{~cm}$ and a voltage of $17 \mathrm{kV}$ was maintained between them. After the initial preparation, the fibres were allowed to dry naturally in a dark environment for $48 \mathrm{~h}$. We used unpolarized ultra-violet radiation $\left(10 \mathrm{~mW} \mathrm{~cm}^{-2}\right.$ and wavelength $\left.365 \mathrm{~nm}\right)$ to perform photo-crosslinking.

Scanning electron microscopy was used to observe the fibre morphology (SEM 360: Cambridge Instruments). Samples of foil coated with the fibres were sectioned from the electrospinning collector plate and mounted onto SEM aluminum stubs via sticky conducting carbon tabs. Samples were then sputter coated with a thin layer of gold prior to examination in the SEM. Image-analysis was conducted with the software, Scandium to determine the diameters of the fibre samples. The fibre diameter was taken as the average of 100 measurements that were randomly selected from across the SEM image. Differential scanning calorimetry (DSC) was used to analyze the thermal properties of the fibres. The DSC used is a TA Instruments TA-Q2000 DSC. DSC was performed in an inert nitrogen atmosphere and all runs were over the temperature interval $20-120^{\circ} \mathrm{C}$.

We used a Deben microtest $200 \mathrm{~N}$ tensile stage to determine the Young's Modulus of the fibres. This tensiometer uses the built-in software to generate plots of fibre extension versus applied force. It was quite difficult to use single fibres since they are quite fragile. Hence, in conducting the experiment, several fibres were bundled together, inserted into the tensiometer and then slowly stretched until the breakage point. The bundles were in the form of rectangular prisms whose dimensions were measured with a digital caliper. In order to test the photochemistry of PVCN, as depicted in Fig. 1, we used a Perkin Elmer Spectrum 100 FTIR spectrometer to compare the spectra of the fibres before and after exposure to UV radiation.

\section{Results and discussion}

Prior to performing any thermal or mechanical measurements on the electrospun fibres, we used scanning electron microscopy (Cambridge S360 SEM) to observe the topology of the fibres and determined the distribution of their diameters with the help of the commercially available software Scandium. These results are captured in Fig. 2. The fibres are essentially smooth cylinders without any ribbon-like or beaded features. The average diameter of the fibres is $2.36 \pm 0.70 \mu \mathrm{m}$. In addition to 1,2 dichloromethane, we were able to generate fibres with a $20 \%$ solution (by weight) of PVCN in dimethylformamide. However, 

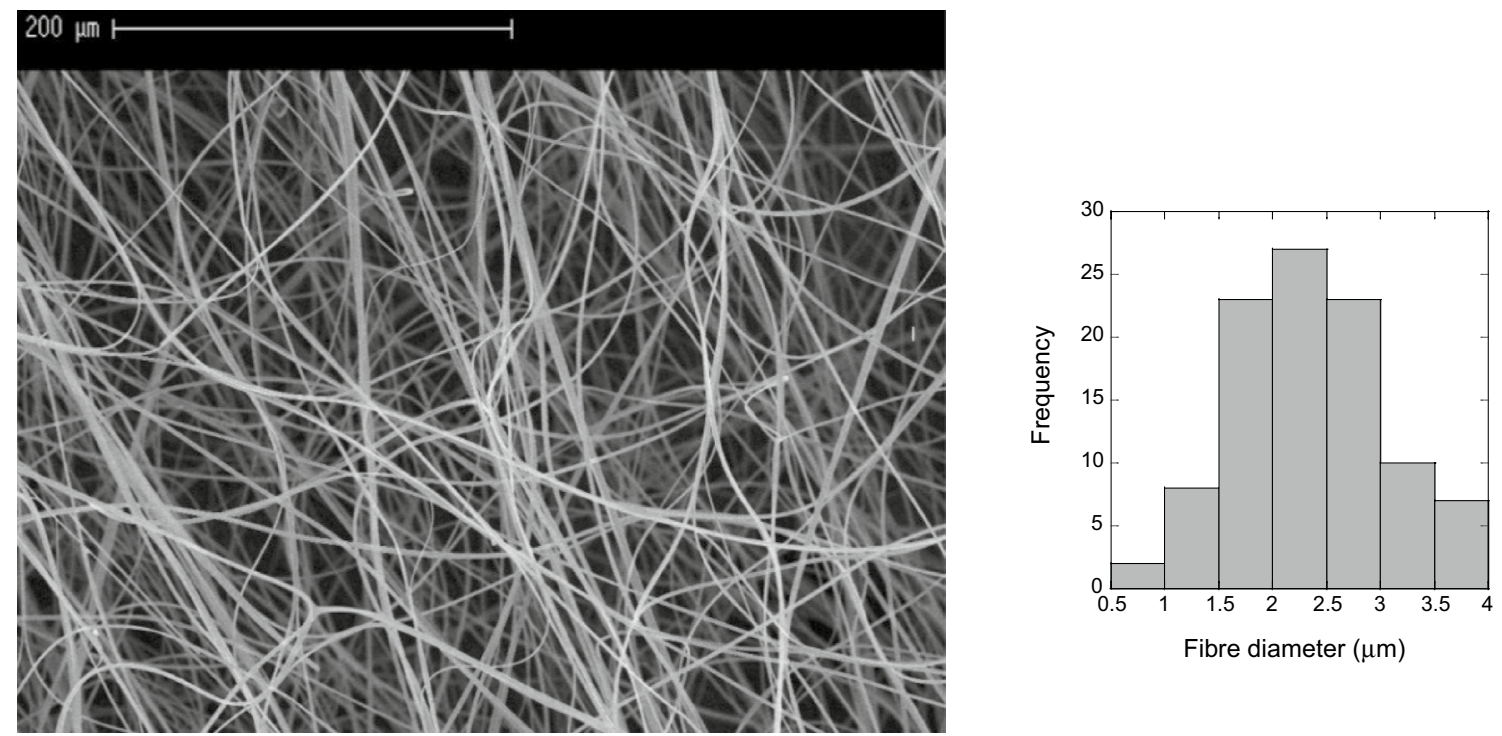

Fig. 2 Topology and distribution of nonirradiated PVCN fibres (Cambridge S360 SEM). The needle-collector separation was $10 \mathrm{~cm}$ and a voltage of $17 \mathrm{kV}$ was maintained between them. The average

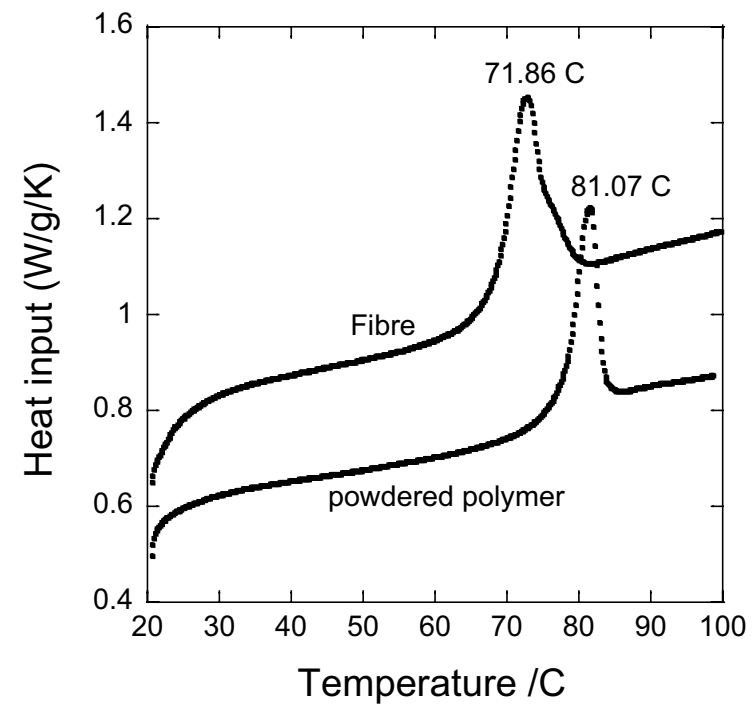

Fig. 3 Enthalpies associated with the glass transitions of the powdered polymer and the fibre (before it was irradiated). The enthalpies are $7.87 \mathrm{~J} / \mathrm{g}$ (powder) and $7.49 \mathrm{~J} / \mathrm{g}$ (fibre)

the fibres were also in the micron range but somewhat beaded. It might be possible to produce PVCN fibres with nanoscale diameters if solutions with lower concentrations are used. Also, we have found that doping PVCN with small amounts of a liquid crystalline polymer resulted in a decrease in the average diameter [33].

The initial characterization of PVCN also includes differential scanning calorimetry (DSC) scans on the fibres and pure PVCN. The glass transition temperatures fibre diameter is $2.36 \pm 0.70 \mu \mathrm{m}$ and this represents the average of 100 measurements randomly selected from across the SEM image

$\left(T_{g}\right)$ of both the powdered sample and fibres of PVCN are marked by unusually large enthalpies. Such large enthalpies represent non-equilibrium thermodynamic states (Fig. 3). The enthalpies associated with the glass transitions of both the powder and the fibre are quite similar; the enthalpy of the fibre is $\sim 5 \%$ less than that of the powder. Hence, electrospinning does not appear to affect the thermal history of PVCN. Despite similar enthalpies, the powdered sample and the fibres show markedly different glass transitions. $\mathrm{T}_{\mathrm{g}}$ of the powder is $81.07 \pm 0.01{ }^{\circ} \mathrm{C}$ while the fibre is $71.86 \pm 0.01{ }^{\circ} \mathrm{C}$. This difference is most likely due to the reduction in the crystallinity of the material during its conversion from the partially crystalline powder to the mainly amorphous fibre [34]. Also, there are no discernible peaks in the cooling curves.

After the initial physical characterization, the electrospun fibres were crossed-linked to different extents by varying the exposure times to UV radiation. Cross-linking enhances thermal stability and this appears as an increase in $\mathrm{T}_{g}$ with increasing exposure times (Fig. 4.). However, the temperature dependence of $\mathrm{T}_{\mathrm{g}}$ with exposure time is nonlinear with the greatest change occurring during the first 10 min of irradiation similar to what was observed by Haramina and Kircheim [29] in their IR spectroscopic studies. $\mathrm{T}_{\mathrm{g}}$ increases by $11.0 \mathrm{~K}$ after the first $10 \mathrm{~min}$ of exposure but only changes by $\sim 0.6 \mathrm{~K}$ for the last $10 \mathrm{~min}$. The peaks associated with the glass transition became more smeared out as radiation times increased. For example, the sample that was irradiated for $1 \mathrm{~h}$ showed a flat and very broad peak which extended for $\sim 20^{\circ} \mathrm{C}$ (enthalpy of $\sim 1 \mathrm{~J} / \mathrm{g}$ ). There 


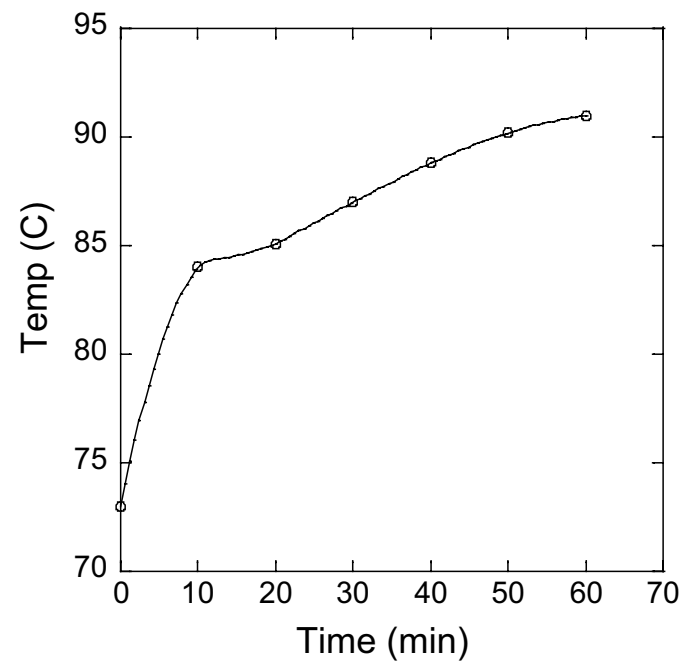

Fig. 4 The variation of glass transition temperatures of cross-linked fibres with exposure times to UV radiation. The error in $\mathrm{T}_{\mathrm{g}} \pm 0.2^{\circ} \mathrm{C}$

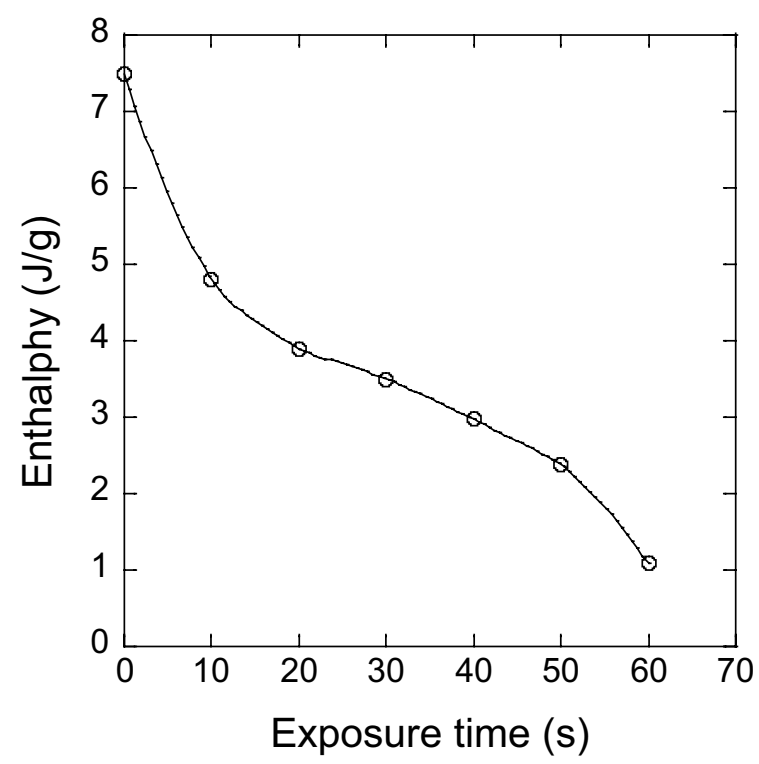

Fig. 5 The enthalpy of the glass transitions of cross-linked samples as a function of exposure time

were no discernible peaks in the DSC scan for an additional 10 min of radiation. The decrease in enthalpy as a function of exposure time is shown in Fig. 5. This is consistent in increased cross-linking and reduced crystallinity.

An empirical relation between the increase in $\mathrm{T}_{g}$ with cross-linking density was developed by Nielson [35] and may be written as:

$\frac{1}{x_{\text {cld }}}=1+\frac{1.2 T_{g 0}}{\Delta T_{g}}$ where $x_{c l d}$ is the cross-linking density (ratio of the number of cross-links to the number of backbone atoms), $T_{g 0}$ the glass transition for zero cross-linking and $\Delta T_{g}\left(T_{g}-T_{g 0}\right)$ the increase in $T_{g}$ with irradiation. Equation (1) implies that a linear relation exists between the inverse cross-linking density and the inverse change in $T_{g}$. The cross-linking densities are extracted from the measured thermal parameters of Eq. 1 and the linear relation is shown in Fig. 6.

Cross-linking is a diffusion-controlled process which is initiated when an unsaturated cross-linker comes within a certain reaction radius of an excited cross-linker. Once the reaction has started, the number of cross-links decays and reaches a steady-state which contains about $20 \%$ of non-cross-linked C $=C$ bonds. Haramina and Kirchheim [29] observed that if spin-coated PVCN films are exposed to UV radiation of wavelength $365 \mathrm{~nm}$ and intensity $10 \mathrm{~mW} \mathrm{~cm}^{-2}$, the most dramatic changes in the IR spectrum occur in the first $10 \mathrm{~min}$. Also, the intensity of the $\mathrm{C}=\mathrm{C}$ bond normalized to the $\mathrm{C}-\mathrm{H}$ bond from FTIR reaches a steady state after about 50-60 m. According to Matsuguchi, Miura and Sakai [36], PVCN will cross-link $100 \%$ only after $48 \mathrm{~h}$ of irradiation. Such irradiation times were impractical for this study and samples were irradiated at most, one hour.

The FTIR spectra of our fibres are shown in Fig. 7. We monitored, in particular, the major peaks that correspond to the $\mathrm{C}=\mathrm{C}$ and $\mathrm{C}=\mathrm{O}$ stretching vibrations of PVCN $\left(1637 \mathrm{~cm}^{-1}\right.$ and $\left.1705 \mathrm{~cm}^{-1}\right)$ and found a substantial increase in transmission (decreased absorption) of both peaks. This reduced intensity in the $\mathrm{C}=\mathrm{C}$ vibrational peak has been previously observed $[29,30,37$, 38]. Also, both studies recorded a shift in the $C=O$ from 1712 to $\sim 1735 \mathrm{~cm}^{-1}$. We observed a shift of just a few

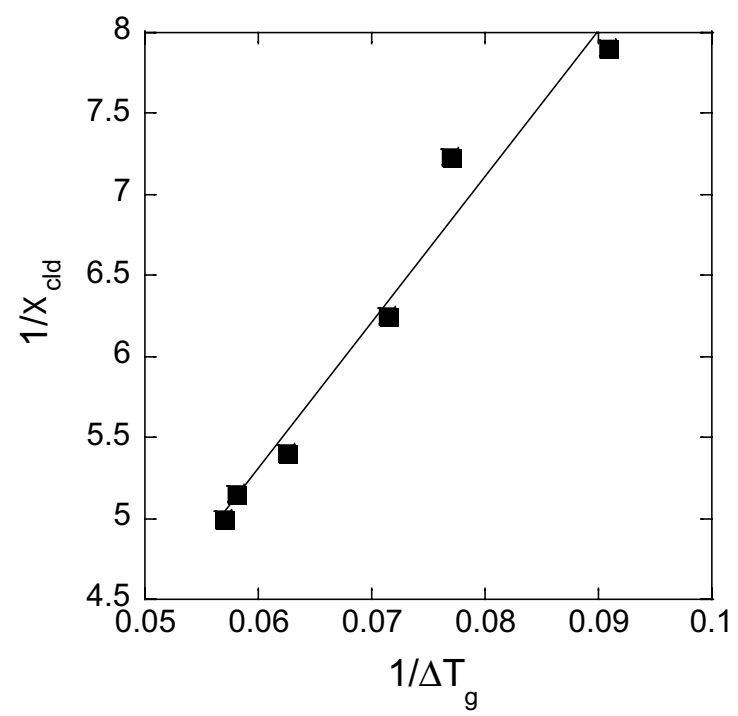

Fig. 6 The variation of the glass transition temperatures with crosslinking density as fitted to the above Nielson equation 


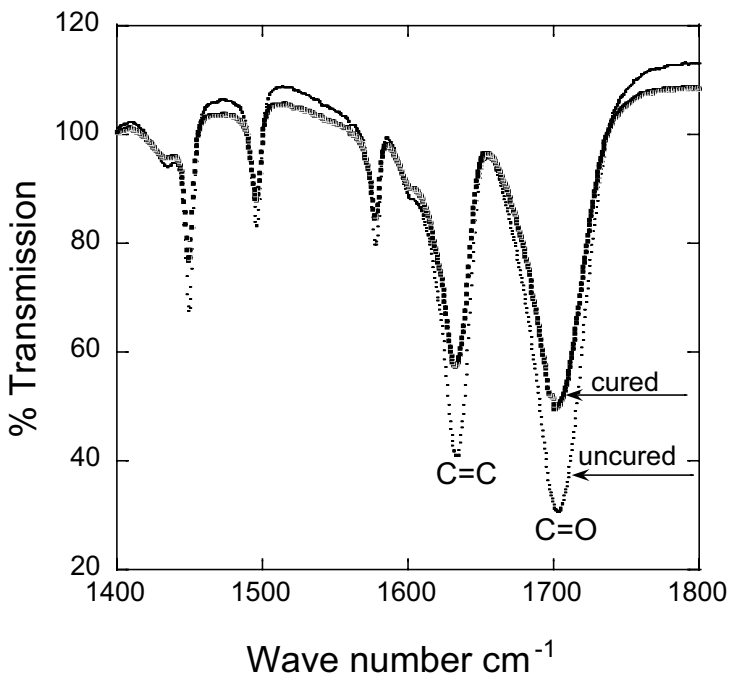

Fig. 7 FTIR spectra of PVCN fibres before and after UV radiation for $1 \mathrm{~h}$

wavenumbers. Solubility studies contained in reference 37 and 38 show that PVCN fibres irradiated for $1 \mathrm{~h}$ develop enough insoluble supports that offer protection against strong solvents. In fact, Lyoo et al. [37]. observed that PVCN is almost insoluble after a mere $10 \mathrm{~min}$ of exposure to UV radiation. This is consistent with our thermal analysis. In Fig. 7 , the transmission is more than $100 \%$ in some areas probably because the sample was on the electrospun foil when scanned. However, we are interested in the change of the dominant peaks and such reflections will not affect our conclusions.

One major focus of this study is to explore quantitatively the effect of cross-linking on mechanical integrity of the fibres as determined by the variation of the Young's modulus with exposure to UV radiation. The Deben tensiometer measures the elongation of the fibres' stress-strain curve for the uncrossed-fibres as shown in Fig. 7. The Young's modulus $(Y)$ is defined by the expression: $Y=\left(\frac{F}{A}\right) \div\left(\frac{\Delta L}{L}\right)$ where $F$ in the stretching force, $A$ the cross-sectional area, $\Delta \mathrm{L}$ the extension and $\mathrm{L}$ the natural length of the fibre. The slope of the initial linear portion of Fig. 7 is given by (YA/L) and this yields the Young's modulus since $L$ and $A$ are measured quantities.

In Fig. 8, there are two linear regions with positive slopes. The first linear region as shown in Fig. 8 was used to determine the Young's modulus. The second region (extensions from $\sim 4.5$ to $10 \mathrm{~mm}$ ) corresponds to the stretching of the fibres that did not initially snap. Little useful information can be deduced from the latter portion since it is virtually impossible to determine the cross-sectional area of the remaining fibres since the experiment would have to be stopped and the surviving fibres would have to be

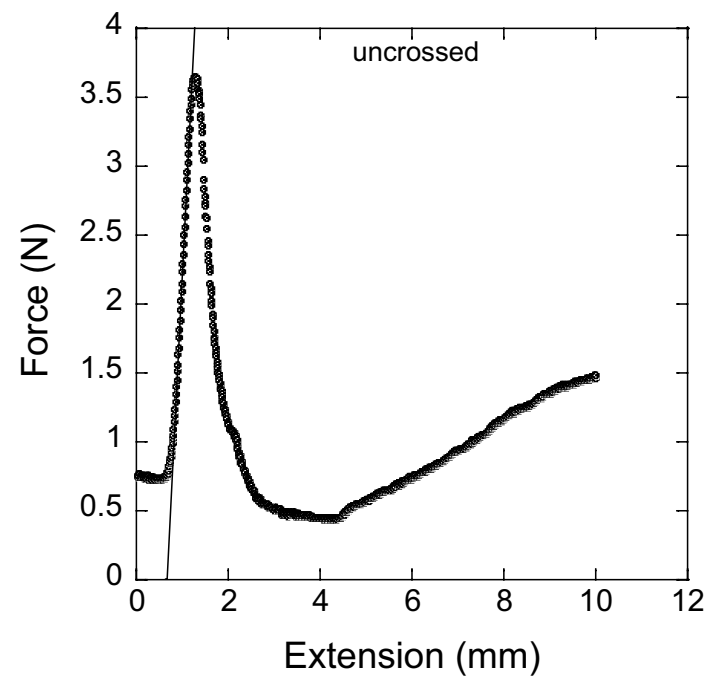

Fig. 8 The stretching force versus extension for uncrossed PVCN fibres was measured with a Deben tensiometer which is fitted with a $200 \mathrm{~N}$ tensile stage. The dimensions of the bundle were: $10 \mathrm{~mm} \times 0.4 \mathrm{~mm} \times 0.4 \mathrm{~mm}$ and the stretching rate was $0.5 \mathrm{~mm} \mathrm{~min}^{-1}$. The Young's modulus is calculated from the slope of the linear region shown

re-bundled. The initial horizontal portion of the curve is ignored in determining the Young's modulus. This flat portion appears in several plots and generates a systematic error which will not affect the calculation of the modulus. Also, there is a well-defined maximum in the curve which is a measure of the yield point. The Young's moduli are plotted in Fig. 9 as a function of exposure times and in Fig. 10 as a function of cross-linking density as calculated (from Eq. 1).

In general, the fibre diameter and the degree of crosslinking strongly influence the Young's moduli of electrospun fibres. For a given material, fibres with the smallest diameters will yield the largest values of Young's moduli (tensile

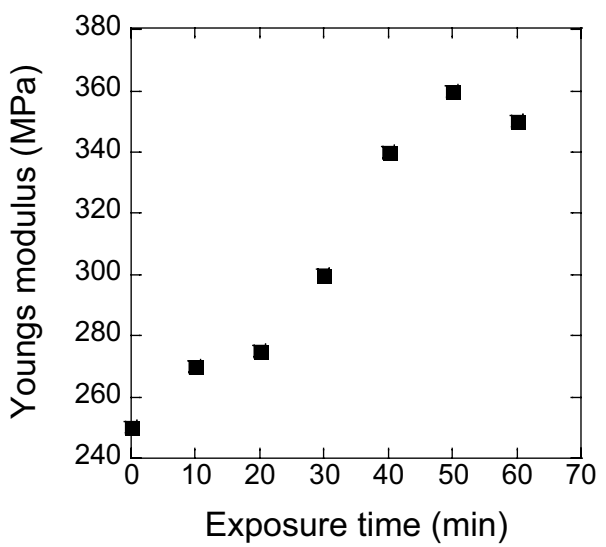

Fig. 9 The variation of Young's modulus with exposure to UV light of intensity $10 \mathrm{~mW} \mathrm{~cm}^{-2}$ and wavelength $365 \mathrm{~nm}$ 


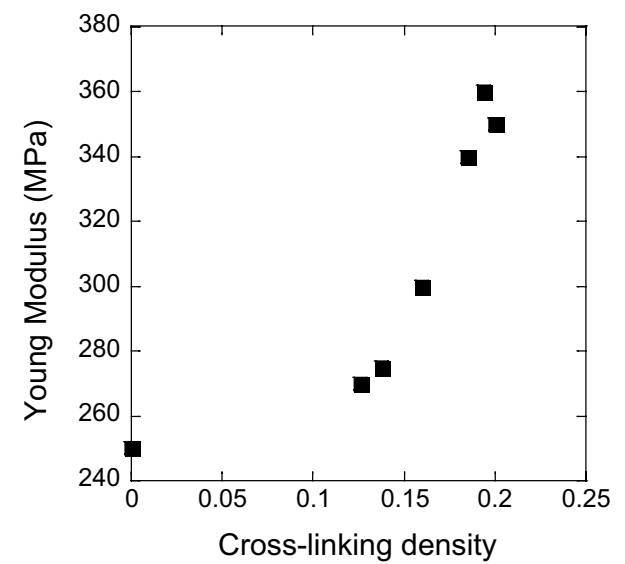

Fig. 10 The variation of Young's moduli with cross-linking density

moduli) [39-41]. This has been attributed to better molecular orientation and crystallinity among smaller diameter fibres as seen by WAXD data [40]. Cross-linking, on the other hand, increases the moduli of electrospun fibres owing to the formation of new covalent bonds which leads to a higher overall energy of bonding [42-44]. Also, different forms of the same material, for example, non-woven mats, cast films, micron-scale or nanoscale fibres all yield different values for the Young's modulus. The largest observed values are for single nanofibers. Wong et al. [40], have determined by direct stress-strain measurements that electrospun fibres of poly ( $\varepsilon$-caprolactone) with small diameters have higher modulus and strength with the effect becoming more pronounced for fibres with diameters less than $\sim 700 \mathrm{~nm}$. This inverse effect has also been observed in silica glass fibres whose moduli lie in the GPa range [46].

It is obvious from our data that there is an increase in the Young's moduli of the fibres with increasing exposure to UV radiation. However, the effect is nonlinear and is consistent with the observed glass transition temperatures which suggest that the majority of cross-linking occurs within the first $10 \mathrm{~min}$ of exposure to UV radiation. The maximum value of the Young's moduli (360 MPa) obtained from our data is $\sim 1.5$ times that for the non-radiated fibre. Our values for the Young's moduli are consistent with previously published values for electrospun fibres [41, 42, 45-47]. For example, incremental stress-strain analysis of single electrospun fibres of poly ( $\varepsilon$-caprolactone) yields a value of $\sim 300 \mathrm{MPa}$ [40]. However, a major source of error in this study lies in the fact that it is virtually impossible to prepare samples with the same volume ratio and this can lead to an uncertainty of $\pm 10 \%$ in the values of the Young's moduli.

\section{Conclusion}

An $18.8 \%$ by weight solution of PVCN in dry 1,2 dichloroethane generated smooth electrospun fibres with an average diameter of $2.36 \pm 0.70 \mu \mathrm{m}$. Owing to the formation of new covalent bonds, exposure to unpolarized ultra-violet radiation $\left(10 \mathrm{~mW} \mathrm{~cm}^{-2} ; 365 \mathrm{~nm}\right)$ resulted in increased glass transition temperatures and larger values of the Young's moduli. However, the majority of cross-linking occurs within the first $10 \mathrm{~min}$ of exposure to UV radiation. Also, the enthalpies accompanying the glass transition becomes more smeared out as the exposure times increased.

We measured the extension of fibre bundles in response to a known applied force and then determined the Young's modulus of the material. We repeated this experiment for fibres that were cross-linking to different extents and quantitatively deduced how the Young's modulus of PVCN fibres varies with UV exposure. The applications of fibres can be greatly enhanced by improving their mechanical integrity which in the case of PVCN can be achieved by cross linking. Hence, it is possible to tailor the mechanical and thermal properties of photo-polymers like PVCN and its derivatives by controlled exposure to ultra-violet radiation.

\section{Compliance with ethical standards}

Conflict of interest On behalf of all authors, the corresponding author states there is no conflict of interest.

\section{References}

1. Greiner A, Wendoff JH (2007) Electrospinning: a fascinating method for the preparation of ultrathin fibers. Angew Chem Int Ed Engl 46(30):5670-5703

2. Reneker DH, Chun I (1996) Nanometre diameter fibres of polymer, produced by electrospinning. Nanotechnology 7:216-223

3. Doshi J, Reneker DH (1995) Electrospinning process and applications of electrospun fibres. J Electrost 35(2-3):151-160

4. Teo WE, Ramakrishna S (2006) A review on electrospinning design and nanofibers assembly. Nanotechnology 1(7):89-106

5. Pillay V, Dott C, Choonara, Tyagi C, Tomar L, Kumar P, du Toit LC, Ndesendo MK (2013) A review of the effect of processing variables on the fabrication of electrospun nanofibers for drug delivery applications. J Nanomater. Article ID 789289

6. Huang Z-M, Zhang Y-Z, Kotaki M, Ramakrishna S (2003) A review on polymer nanofibers by electro-spinning applications in nanocomposites. Compos Sci Technol 63:2223-2253

7. Shi X, Zhou W, Ma D, Ma Q, Bridges D, Ma Y, Hu A (2015) Electrospinning of nanofibers and their applications for energy devices. J Nanomater. Article ID 140716

8. Park J-S (2010) Electrospinning and its applications. Adv Natl Sci Nanosci Nanotechnol 1:043002

9. Xue J, Xie J, Liu W, Xia Y (2017) Electrospun nanofibers: new concepts, materials and applications. Acc Chem Res 50:1976-1987 
10. Kaur S, Sundarrajan Rana D, Sridhar R, Gopal R, Matsuura T, Ramakrishna S (2014) Review: the characterization of electrospun nanofibrous liquid filtration membranes. J Mater Sci 49:6143-6159

11. Filiz BC, Figen AK (2016) Fabrication of electrospun nanofiber catalysts and ammonia borane hydrogen release efficiency. Int J Hydrog Energy 41(34):15433-15442

12. Formo E, Lee E, Campell D, Xia Y (2008) Functionalization of electrospun $\mathrm{TiO}_{2}$ nanofibres with Pt nanoparticles and nanowires for catalytic applications. Nano Lett 8:668-672

13. Lu P, Xia Y (2013) Novel nanostructures of rutile fabricated by templating against yarns of polystyrene nanofibrils and their catalytic applications. ACS Appl Mater Interfaces 5:6391-6399

14. Formo E, Yavuz MS, Lee EP, Layne L, Xia Y (2009) Functionilization of electrospun ceramic nanofibre membranes with noblemetal nanostructures for catalytic applications. J Mater Chem 19:3878-3888

15. Liu W, Thomopoulos S, Xia Y (2012) Electrospun nanofibres for regenerative medicine. Adv Healthc Mater 1:10-25

16. Xie J, MacEwan M, Ray WZ, Liu W, Siewe DY, Xia Y (2010) Electrospun nanofibres for neural tissue engineering. Nanoscale 4:35-44

17. Sharma P, Maffulli N (2006) Biology of tendon injury: healing modeling and remodeling. J Musculosket Interact 6:181-190

18. Ahn YC, Park SK, Kim GT, Hwang YJ, Lee CJ (2006) Development of high efficiency nanofilters made of nanofibres. Curr Appl Phys 6(6):1030-1035

19. Jeong EH, Yang J, Youk JH (2007) Preparation of polyurethane cationomer nanofiber mats for use in antimicrobial nanofilter applications. Mater Lett 61(18):3991-3994

20. Kattamuri N, Shin JK, Kang B, Lee CG, Lee JK (2005) Development and surface characterization of positively charged filters. J Mater Sci 40(17):4531-4539

21. Gopal R, Kaur S, Chan C, Ramakrishna S, Tabe S, Matsuura T (2007) Electrospun nanofibrous polysulfone membranes as prefilters: particulate removal. J Membr Sci 289:210-219

22. Balamurugan R, Sundarrajan S, Ramakrishna S (2011) Recent trends in nanofibrous membranes and their suitability for air and water filtration. Membranes 1:232-248

23. Gibson PW, Schreuder-Gibson HL, Pentheny C (1998) Electrospinning technology: direct applications of tailorable ultrathin membranes. J Coat Fabr 28:63

24. Nattanmai Raman D, Gopalu K, Rangraj S, Palanisamy M, Venkatachalam R (2014) Electrospun MgO/nylon6, hybrid nanofibres for protective clothing. Nano-Micro Lett 6(1):46-54

25. Huang I, Nagapudi K, Apkarian RP, Chaikof EL (2001) Engineered collagen-PEO nanofibres and fabrics. J Biomater Sci Polym Ed 12(9):979-993

26. Reyes CG, Sharma A, Lagerwall Jan PF (2016) Non-electronic gas sensors from electrospun mats of liquid crystal core fibres for detecting volatile organic compounds at room temperature. Liq Cryst 43:1986-2001

27. Wang XY, Lee SH, Drew C, Senecal KJ, Kumar J, Samuelson LA (2002) Electrospun nanofibrous membranes for highly sensitive optical sensors. Nano Lett 2(11):1273-1275

28. Tong $L$ (2018) Micro/nanofibre optical sensors: challenges and prospects. Sensors 18:903-930

29. Haramina T, Kirchheim R (2007) Mechanical spectroscopy of PVCN with increasing cross-linking degree. Macromolecules 40:4211-4216

30. Gupta P, Trenor SR, Long TE, Wilkes GL (2004) In situ photocross-linking of cinnamate functionalized poly (methyl methacrylate-co-2-hydroxyethyl acrylate) fibers during electrospinning. Macromolecules 37(24):9211-9218

31. Sung SJ, Cho KY, Yoo JH, Kim SB, Chang HS, Cho I, Park JK (2004) Dimerization behavior of cinnamate group attached to flexible polymer backbone and its effect on the molecular orientation. Chem Phys Lett 394:238-243

32. Sung SJ, Cho KY, Park JK (2004) Photo-induced liquid crystal alignment of poly (vinyl cinnamate) and fluorinated polyimide blends. Mater Sci Eng C 24(1-2):181-184

33. Singh U, Davis F, Mohan S, Mitchell G (2013) Electro-active nanofibers electrospun from blends of poly-vinyl cinnamate and a cholesteric liquid crystalline silicone polymer. J Mater Sci 48(21):7613-7620

34. Zong XH, Kim K, Fang DF, Ran SF, Hsiao BS, Chu B (2002) Structure and process relationship of electrospun bioabsorbable nanofiber membranes. Polymer 3(16):4403-4412

35. Nielsen LE (1969) Cross-linking-effect on physical properties of polymers. J Macromol Sci Part C 3:69-103

36. Matsuguchi M, Miura J, Sakai Y (2000) Effect of crosslinking structure on sorption of $\mathrm{CO}_{2}$ in photocrosslinked PVCA film. J Appl Polym Sci 78:1744-1750

37. Lyoo WS, Youk JH, Lee SW, Park WH (2005) Preparation of porous ultra-fine poly(vinyl cinnamate) fibres. Mater Lett 59(28):3558-3562

38. Armstrong MR, Arredondo YYA, Liu C-Y, Stevens JE, Mayhob A, Shan B, Senthilnathan S, Balzer CJ, Bin Mu (2015) Uio-66 and poly(vinyl cinnamate) nanofiber nanocomposite membranes synthesized by a facile three-stage process. Ind Eng Chem Res $54: 12386-12392$

39. Bellan LM, Kameoka J, Craighead HG (2005) Measurement of the Young's moduli of individual polyethylene oxide and glass nanofibres. Nanotechnology 16:1095-1099

40. Wong S, Baji A, Leng S (2008) Effect of fiber diameter on tensile properties of electrospun poly(e-caprolactone). Polymer 49:4713-4722

41. Yao J, Bastiaansen CWM, Peijs T (2014) High strength and high modulus electrospun nanofibers. Fibres 2:158-186

42. Wang S, Kempen DH, Simha NK, Lewis Jl, Windebank AJ, Yaszemski MJ, Lu L (2008) Photo-crosslinked hybrid polymer networks consisting of poly(propylene fumarate) (PPF) and poly(caprolactone fumarate) (PCLF): controlled physical properties and regulated bone and nerve cell responses. Biomacromolecules 9(4):1229-1241

43. Giebel E, Getze J, Röcker T, Greiner A (2013) The importance of crosslinking and glass transition temperature for the mechanical strength of nanofibers obtained by green electrospinning. Macrol Mater Eng 298:439-446

44. Yang L, Van der Werf KO, Fitié CFC, Bennink ML, Dijkstra PJ, Feijen $J$ (2008) Mechanical properties of native and cross-linked type I collagen fibrils. Biophys J 94(6):2204-2211

45. Islan A, Yasin T, Rafiq MA, Shah TH, Sabir A, Khan SM, Jamil T (2015) In-situ crosslinked nanofiber mats of chitosan/poly(vinyl alcohol) blend: fabrication, characterization and MTT assay with cancerous bone cells. Fibres Polym 16(9):1853-1860

46. Ramdhanie LI, Aubuchon SR, Boland ED, Knapp DC, Barnes PC, Simpson DG, Wnek GE, Bowlin GL (2006) Thermal and mechanical characterization of electrospun blends of poly(lactic acid) and poly(glycolic acid). Polym J 389:1137-1145

47. Baker SR, Banarjee S, Bonin K, Guthold M (2016) Determining the mechanical properties of electrospun poly- $\varepsilon$-caprolactone (PCL) nanofibers using AFM and a novel fiber anchoring technique. Mater Sci Eng Mater Biol Appl 59:203-212 